\title{
Synteny (co-linearity) in some cereal crops genomes as revealed by amplified fragment length polymorphisms (AFLP), simple sequence repeats (SSR) and inter simple sequence repeats (ISSR) markers
}

\author{
Haddad El Rabey ${ }^{1,3 *}$, Jalaluddin A. Khan ${ }^{1}$, Abdulrahman L. Al-Malki ${ }^{1}$ and Hussein K. \\ Hussein $^{2,4}$
}

${ }^{1}$ Biochemistry Department, Faculty of Science, King Abdulaziz University, Jeddah, Saudi Arabia Kingdom (KSA).

${ }^{2}$ Department of Biological Sciences, Faculty of Science, King Abdulaziz University, Jeddah, Saudi Arabia Kingdom (KSA).

${ }^{3}$ Permanent address: Bioinformatics Department, Genetic Engineering and Biotechnology Institute, Minufiya University, Sadat City, Egypt.

${ }^{4}$ Permanent address: Zoology Department, Faculty of Science, Alexandria University, Egypt.

Accepted 22 June, 2012

\begin{abstract}
Genomes of barley, maize, rice, wheat and sorghum were characterized based on three different molecular markers based on DNA sequence namely; Amplified Fragment Length Polymorphisms (AFLP), Simple Sequence Repeats (SSR) and Inter Simple Sequence Repeats (ISSR) markers. Five AFLP primer combinations were used for fingerprinting six cultivars which belongs to barley, rice and wheat cultivars leading to the production of numerous AFLP bands, $\mathbf{3 0 0}$ of them were polymorphic. Thirty SSR markers were obtained from fingerprinting eight cultivars belonging to the five studied species using 11 SSR primers, whereas 91 ISSR markers were obtained from fingerprinting the same cultivars using 10 ISSR primers. All data were analyzed using Numerical Taxonomy System of Multivariate Statistical (NTSYS-pc) software packages to address the relationship and studying the synteny between the genomes of the five cereal species. The resulted dendrogram revealed that rice, barley and wheat genomes are more related to each other than sorghum and maize genomes that appeared close relatedness to each other but distant from other cereal's genomes under study. Barley and wheat genomes revealed close relatedness to each other compared to rice genome.
\end{abstract}

Key words: Amplified fragment length polymorphisms (AFLP), simple sequence repeats (SSR), inter simple sequence repeats (ISSR), wheat, barley, rice, synteny.

\section{INTRODUCTION}

The family Poaceae contains the most economic cereals; the cultivated barley (Hordeum vulgare L.) and wheat

${ }^{*}$ Corresponding author. E-mail: elrabey@hotmail.com.

Abbreviations: RFLP, Restriction fragment length polymorphism; RAPD, randomly amplified polymorphic DNA; AFLP, amplified fragment length polymorphism; SSR, simple sequence repeats; SNPs, single nucleotide polymorphism; PCR, polymerase chain reaction; ISSR, inter simple sequence repeats.
(Triticum aestivum L.) belong to tribe Triticeae, maize (Zea mays L.) belongs to the tribe Andropogonae, whereas the cultivated rice (Oryza sativa L.) belongs to tribe Oryzeae and both tribes belong to the family Poaceae, whereas Sorghum (Sorghum bicolor L.) belongs to the tribe Andropogoneae of the same family. The food and agriculture organization (FAO) report (1985) ranked wheat as the most important crop plant followed by rice, maize and then barley.

Barley, wheat, rice, sorghum and maize are very important crops for human diet and animal forage. These 
staple food cereal crops are thought to be derived from an ancestral plant about 60 million years ago. This relatively recent evolutionary event means that their genome structures might be conserved. Rice has the most compact genome among them. This has been suggested by mutual mapping of molecular markers among rice, maize, wheat and barley (Moore et al., 1995). The genomes of grass species vary enormously in size. The smallest at $400 \mathrm{Mb}$, is found in rice; the largest at $17000 \mathrm{Mb}$ is found in wheat. Although some of the differences in genome size result from the fact that wheat is an allohexaploid, whereas rice is diploid, a far more important factor is the large variation from one species to the other in types and amount of repetitive DNA se-quences present (Hartl and Jones, 2001).

Previous studies showed that all cereal crops are closely related to each other and the whole group of Triticeae can be considered as a single gene pool because of the similarity of genetic contents and the colinearity of gene loci of the chromosomes of barley and other members of Triticeae particularly wheat and to a limited and partially useful synteny between wheat and rice chromosomes (Islam, 1983; Islam and Shepherd, 1992; Mohler and Jahoor, 1996 and Gallego et al., 1998; Liu et al., 2006; Messing, 2009).

Moore (1992) and Moore et al. (1995) reported that, although wheat has one of the largest genomes $(1.7 \times$ $\left.10^{10} \mathrm{bp}\right)$ and rice has one of the smallest plant genomes $\left(4 \times 10^{8} \mathrm{bp}\right)$. It has been observed that a significant microsynteny is present between the two genomes. Meanwhile, Gallego et al. (1998) reported that comparative genetic mapping among cereal genomes has demonstrated that homologous single-copy sequences or genes are collinear on the restriction fragment length polymorphism (RFLP) maps of wheat, barley, rye, oat, maize and rice. This has allowed the maps of several members of the Gramineae family to be compared and the synteny of these genomes to be defined. The Lr10 leaf rust resistance gene on wheat chromosome 1AS cosegregates with the $L r k 10$ receptor-like kinase gene. The rice gene corresponding to Lrk10 is mapped on rice chromosome 1. This region corresponds to the distal part of barley chromosome $3 \mathrm{H}$ and wheat chromosomes $3 \mathrm{~A}$ and $3 \mathrm{~B}$, suggesting that the synteny is conserved between rice chromosome 1 and the Triticeae group $3 S$ chromosomes up to the telomere of the chromosomes. Bennetzen and May (2003) studied the genetic colinearity of rice and maize, rice, sorghum, barley and wheat on the basis of genomic sequence analysis. Yang and Bennetzen (2009) studied the distribution, diversity, evolution, and survival of Helitrons in the maize genome.

The synteny between barley and rice genomes was evident through several studies. Leister et al. (1999) identified homology of resistance genes present in both barley and rice. At the same time, Druka et al. (2000) found that a synteny at high resolution levels has been established between the region of barley chromosome
$7(5 \mathrm{H})$ containing the rpg4 locus and the subtelomeric region of rice chromosome 3 between markers S16474 and E10757. Smilde et al. (2001) using rice expressed tags, scored a synteny between rice chromosome 1 and barley chromosome $3 \mathrm{H}$. Buell et al. (2005) stated that rice (O. sativa L.) chromosome 3 is evolutionarily conserved across the cultivated cereals and shares large blocks of synteny with maize and sorghum, which diverged from rice more than 50 million years ago.

Hartl and Jones (2001) stated that each chromosome in wheat contains approximately 25 times as much DNA as each chromosome in rice. Yu et al. (2002) produced a draft sequence of the rice genome for the most widely cultivated subspecies in China, $O$. sativa L. ssp. indica, by whole-genome shotgun sequencing. The genome was 466 megabases in size, with an estimated 46,022 to 55,615 genes. El Rabey et al. (2006) analyzed the maize genome and studied the intercultivar relationships of 7 maize varieties based on biochemical and molecular markers. Wicker et al. (2009) studied the intraspecific diversity in wheat and barley genomes and identified breakpoints of ancient haplotypes and provided insight into the structure of diploid and hexaploid Triticeae gene pools.

In the last two decades, the discontinuous molecular makers such as RFLP, randomly amplified polymorphic dna (RAPD), amplified fragment length polymorphism (AFLPs), simple sequence repeats (SSR) and single nucleotide polymorphism (SNPs) have been used as genetic markers for measuring the genetic differences existing in the genomes, because they measures homology in DNA sequence. These markers have been traditionally used by plant geneticists and breeders to study intraspecific genetic variability (Heun et al., 1997; Badr et al., 2000; El Rabey et al., 2002). They have also the potential to assist in interspecific comparisons (Bachmann, 1998). They reveal variations in nucleotide sequences (polymorphism) and are used for genetic analysis because, at an allelic locus, they are inherited according to Mendel's laws. This characteristic makes it possible to calculate the genetic distance between taxa and to summarize the results in genetic maps. Powell et al. (1996) suggested that AFLPs provide high levels of delineation of complex genetic structures, whereas Winfield et al. (1998) suggested AFLPs as reliable and informative multilocus probes. Furthermore, Huang et al. (2000) stated that the AFLP markers are combining the features of RFLP and polymerase chain reaction (PCR) while avoiding the disadvantages encountered in these DNA markers. The AFLP markers were efficiently used in the analysis of the genetic diversity for genetic map construction and cultivar differentiation in barley (Becker et al., 1995 and El Rabey et al., 2002), wheat (Burkhamer et al., 1998; Huang et al., 2000) and rice (Mackill et al., 1995; Gustafson and Yano, 2000).

Bennetzen and May (2003) mentioned that many more studies to compare orthologous genome organization in 
rice and other cereals are needed. So, the aim of the current study is to conduct the same line in discovering more colinearity among the four cereal genomes using advanced molecular technologies based on DNA amplification and sequencing and consequently comparison of data with those deposited in the bioinformatics databases for application purposes in cereal crops improvement.

In the present study an attempt was made in order to prove the actual relationships among the five cereal crops through comparison of their genetic composition reflected by DNA fingerprinting based molecular markers used on DNA sequence such as AFLP, inter simple sequence repeats (ISSR) and SSR markers and other molecular data from bioinformatics databases.

\section{MATERIALS AND METHODS}

\section{First experiment}

Seeds of six cultivars representing three cereal crops: barley (ACSAD and ALEXIS), rice (Egyptian Jasmine and Sakha 101), and wheat (Gemmiza 3 and Giza 160) were used. Barley cultivars were obtained from the Desert Research Center, whereas wheat and rice seeds were obtained from the National Research Center, Giza, Egypt.

\section{DNA extraction and amplified fragment length polymorphisms (AFLP) fingerprinting}

The seeds were grown under greenhouse conditions and young leaves of three to five actively growing plants were collected in sterilized $50 \mathrm{ml}$ polypropylene tubes and immediately frozen in liquid nitrogen. $0.3 \mathrm{~g}$ of the frozen plant materials were ground in liquid nitrogen using mortar and pistil. DNA was extracted immediately using the CTAB method (Saghai-Maroof et al., 1984).

AFLP fingerprinting was performed using the method of Vos et al. (1995), with the omission of streptavidin beads. Five primer combinations namely, E36/M41, E37/M40, E40/M40, E40/M41, and E37/M41 were constructed by MWG-Biotech GmbH, Ebersberg, Germany and were used for PCR amplification. The sequences of these primers are as follows: (EcoRI primers: E36: 5-GAC TGC GTA CCA ATT C ACC-3, E37: 5-GAC TGC GTA CCA ATT C ACG3, E40: 5-GAC TGC GTA CCA ATT C AGC-3, Msel primers: M40: 5-GAT GAG TCC TGA GTA A AGC-3, M41: 5-GAT GAG TCC TGA GTA A AGG-3).

The amplified fragments were separated on $4.5 \%$ polyacrylamide gels and exposed to X-ray film (Hyperfilm-MP; Amersham Pharmacia) at room temperature to visualize the bands as autoradiographs.

\section{Second experiment}

Eight samples representing barley, maize, rice, sorghum and wheat were further investigated using SSR and ISSR to address their relationship to each other and study the synteny between the genomes of the five species. Barley was represented by two samples from Jazan and Qassim, wheat was represented by Sakha 1 and Sids 1, rice is represented by Sakha 101 and a maize sample and two sorghum samples (white and red) from Jeddah market.

\section{Microsatellite (SSR) assay}

11 SSR markers were selected to represent the entire rice genome based on the published framework map (Akagi et al. 1996; Temnykh et al., 2000) and were tested in the other genomes under study. These primers were constructed by Metabion International AG, D-82152 Martinsried, Germany). The loci, chromosomal location, primer sequence, annealing temperature (Tm) and fragment size are presented in Table 1.

DNA amplification was carried out in $25 \mu$ reaction mixture containing $50 \mathrm{ng}$ genomic DNA in $5 \mu \mathrm{l}, 2.5 \mu \mathrm{l}$ 10X PCR buffer, $2 \mu \mathrm{l}$ $\mathrm{mM} \mathrm{MgCl} 2,2 \mu \mathrm{l}$ of each of the forward and reverse primers (10 PM), $2.5 \mu \mathrm{l}$ of $0.2 \mathrm{mM}$ dNTPs (from Promega) and $0.5 \mu \mathrm{l}$ Taq DNA polymerase (GoTaq Flexi DNA polymerase from Promega) and 8.5 $\mu \mathrm{l}$ didistilled deionized water. PCR amplification was carried out as described by Temnykh et al. (2000) as follows: $5 \mathrm{~min}$ at $94^{\circ} \mathrm{C}$ followed by 35 cycles of $1 \min 94^{\circ} \mathrm{C}, 1 \mathrm{~min} 55^{\circ} \mathrm{C}$ and $2 \min$ at $72^{\circ} \mathrm{C}$, with a final extension of $5 \mathrm{~min}$ at $72^{\circ} \mathrm{C}$. The amplification product was resolved on $1.5 \%$ agarose gel against $1 \mathrm{~kb}$ DNA ready load ladder from Solis BioDyne, Riia 185a, 51014 Tartu, Estonia.

\section{Inter simple sequence repeats (ISSR) fingerprinting}

Ten specific ISSR primers were constructed by Metabion International AG, D-82152 Martinsried, Germany) for fingerprinting the studied genotypes of barley, maize, rice, sorghum and wheat as presented in Table 2. Amplification which was carried out in $20 \mu \mathrm{l}$ reaction consists of $4 \mu \mathrm{l}$ master mix $(5 \times$ Fire Pol Master Mix from Solis BioDyne, Riia 185a, 51014 Tartu, Estonia), $2 \mu \mathrm{l} 10$ PM of each primer, 50 to $100 \mathrm{ng}$ genomic DNA in $2 \mu \mathrm{l}$ and $12 \mu \mathrm{l}$ of sterilized distilled water. The reaction was carried out in Biorad thermocycler programmed as follows: denaturation (one cycle) $94^{\circ} \mathrm{C}$ for 2 minutes, followed by 30 cycles $\left(94^{\circ} \mathrm{C}\right.$ for $30 \mathrm{~s}, 44^{\circ} \mathrm{C}$ for $45 \mathrm{~s}, 72^{\circ} \mathrm{C}$ for $1 \mathrm{~min}$ and $30 \mathrm{~s}$ ) and finally one cycle at $72^{\circ} \mathrm{C}$ for 20 min. The PCR product was separated against $100 \mathrm{bp}+1.5 \mathrm{~Kb}+3$ $\mathrm{Kb}$ DNA Ladder was purchased from SibEnzyme Ltd, Russia on $1.5 \%$ agarose gel. The ISSR bands were detected on UVtransilluminator and photographed by Gel documentation system. Table 2 shows the name and sequence of the 10 ISSR primers used in fingerprinting the genotypes under study.

\section{Scoring and analysis of data}

AFLP autoradiographs as well as SSR and ISSR data were scored as binary system where 1 and 0 indicate the presence or absence of a particular band, respectively. All data were analyzed using the Numerical Taxonomy System of Multivariate Statistical Program (NTSYS-pc) software package version 1.8 (Rohlf, 1993). The data were computed using SAHN (Sequential, Agglomerative, Hierarchical, and Nested methods) cluster analysis (Sneath and Sokal, 1973). The rooted trees were constructed using the UPGMA method (Sokal and Michener, 1958).

\section{RESULTS}

\section{First experiment}

Three hundred polymorphic AFLP bands were produced as a result of fingerprinting the six cultivars of barley, rice and wheat using the five primer combinations. Figure 1 shows examples of digested and amplified DNA using AFLP technology for the six taxa of the first experiment using primer combination E36/M41. Table 3 shows the 
Table 1. Name, sequence, chromosomal location, number of amplicons and melting temperature of SSR markers used in investigating cereal samples under study.

\begin{tabular}{|c|c|c|c|c|}
\hline Primer name & Sequence & $\begin{array}{c}\text { Chromosomal } \\
\text { location }\end{array}$ & $\begin{array}{c}\text { No. of amplicons } \\
\text { resuted }\end{array}$ & $\begin{array}{c}\text { Temperature } \\
\text { (C) }\end{array}$ \\
\hline LEA f: & 5-ATGGCTCGCTGCTCTTACTC-3 & \multirow{2}{*}{$5(\mathrm{H})$} & \multirow{2}{*}{1} & 60 \\
\hline LEA r: & 5-TCAGTGAGAGGATCGATTGAAC-3 & & & 60 \\
\hline MGB391 F: & 5'-AgСТССТTTССТСССТTCC-3' & \multirow{2}{*}{$2(2 \mathrm{H})$} & \multirow{2}{*}{1} & 59 \\
\hline MGB391 R: & 5'-ССААСАТСТССТССТССТgА-3' & & & 60 \\
\hline MGB396 F: & 5'-CgCTAgCTTgTTTCTCgTTTg-3' & \multirow{2}{*}{$4(4 \mathrm{H})$} & \multirow{2}{*}{3} & 59 \\
\hline MGB396 R: & 5'-TCgCATggCATCAACTACAg-3' & & & 58 \\
\hline MGB402 F: & 5'-CAAgCAAgCAAgCAgAgAgA-3' & \multirow{2}{*}{$5(1 \mathrm{H})$} & \multirow{2}{*}{4} & 58 \\
\hline MGB402 R: & 5'-AACTTgTggCTCTgCgACTC-3' & & & 60 \\
\hline MGB371 F & 5'-САССАAgTTCAССТСgТССТ-3' & \multirow{2}{*}{$6(6 \mathrm{H})$} & \multirow{2}{*}{4} & 60 \\
\hline MGB371 R: & 5'-TTATTCAggCAGCACCATTg-3' & & & 56 \\
\hline Bmag149 F: & 5'-CAAgCCAACAgggTAgTC-3' & \multirow{2}{*}{$5(1 \mathrm{H})$} & \multirow{2}{*}{1} & 56 \\
\hline Bmag149 R: & 5'-ATTCggTTTCTAgAggAAgAA-3' & & & 55 \\
\hline MGB356 F: & 5'-TggTCTggAgCTCTCAACAg-3' & \multirow{2}{*}{$6(6 \mathrm{H})$} & \multirow{2}{*}{1} & 60 \\
\hline MGB356 R: & 5'-AAgCCACATTgAAggAgCAC-3' & & & 58 \\
\hline Bmag210 F: & 5'-ACCTACAgTTCAATAgCTAgTACC-3' & \multirow{2}{*}{$6(6 \mathrm{H})$} & \multirow{2}{*}{1} & 62 \\
\hline Bmag210 R: & 5'-gCACAAAACgATTACATCATA-3' & & & 54 \\
\hline MGB384 F: & 5'-CTgCTgTTgCTgTTgTCgTT-3' & \multirow{2}{*}{$7(5 \mathrm{H})$} & \multirow{2}{*}{6} & 58 \\
\hline MGB384 R: & 5'-ACTCggggTCCTTgAgTATg-3' & & & 60 \\
\hline BMS02F: & 5'-AgAgTAgTggAAAgAAAgTT-3' & \multirow{2}{*}{$7(5 \mathrm{H})$} & \multirow{2}{*}{6} & 52 \\
\hline BMS02 R: & 5'-TggTAgTgAgATgAggTgAC-3' & & & 58 \\
\hline \multirow{2}{*}{$\begin{array}{l}\text { MGB318 F: } \\
\text { MGB318 R: }\end{array}$} & 5'-CggCTCAAggTСТСТTСТTC-3' & \multirow[b]{2}{*}{$7(5 \mathrm{H})$} & \multirow[b]{2}{*}{2} & 60 \\
\hline & 5'-TATCTCAgATgCСССТTTCC-3' & & & 58 \\
\hline Total & & & 30 & \\
\hline
\end{tabular}

frequency of presence or absence of a specific AFLP marker in the various taxa under study. Sixty four bands were found common to all studied taxa but absent in one or more cases. Twelve bands were common only to the two barley cultivars, 50 bands were common only to the two rice cultivars and 28 bands were common to the two wheat cultivars. Twenty bands were common to all barley and rice cultivars, another 20 bands were common to all rice and wheat cultivars and 35 bands were common to all wheat and barley cultivars. Twenty one bands were polymorphic in barley and rice cultivars, 29 bands were polymorphic in rice and wheat cultivars and 21 bands were found polymorphic in barley and wheat cultivars. This means that 56 bands were common to barley and wheat, 49 bands were common to wheat and rice and 41 bands were common to barley and rice. Six primers failed to amplify any SSR in the studied cereal samples.

\section{Amplified fragment length polymorphisms (AFLP) data analysis}

The scored AFLP data (300 AFLP fragments) were analyzed using NTSYS-pc program to address the 
Table 2. ISSR primers used in fingerprinting the studied cultivars, their names, sequence and number and the molecular weight of markers produced.

\begin{tabular}{lccc}
\hline Primer name & Sequence & No. of markers resulted & Marker molecular weight bp \\
\hline ISSR-814 & $(\mathrm{CT})_{8}$ TG & 8 & $380-680$ \\
ISSR-844A & $(\mathrm{CT})_{8} \mathrm{AC}$ & 9 & $400-1100$ \\
ISSR-844B & $(\mathrm{CT})_{8} \mathrm{GC}$ & 7 & $380-1100$ \\
ISSR-HB 8 & $(\mathrm{GA})_{6} \mathrm{GG}$ & 6 & $650-1200$ \\
ISSR-HB 9 & $(\mathrm{GT})_{6} \mathrm{GG}$ & 10 & $420-1500$ \\
ISSR-HB10 & $(\mathrm{GA})_{6} \mathrm{CC}$ & 11 & $300-900$ \\
ISSR-HB11 & $(\mathrm{GT})_{6} \mathrm{CC}$ & 7 & $240-700$ \\
ISSR-HB13 & $(\mathrm{GAG})_{3} \mathrm{GC}$ & 9 & $300-750$ \\
ISSR-HB14 & $(\mathrm{CTC})_{3} \mathrm{GC}$ & 17 & $200-1200$ \\
ISSR-HB15 & $(\mathrm{GTG})_{3} \mathrm{GC}$ & 7 & $250-1400$ \\
Total & & 91 & \\
\hline
\end{tabular}
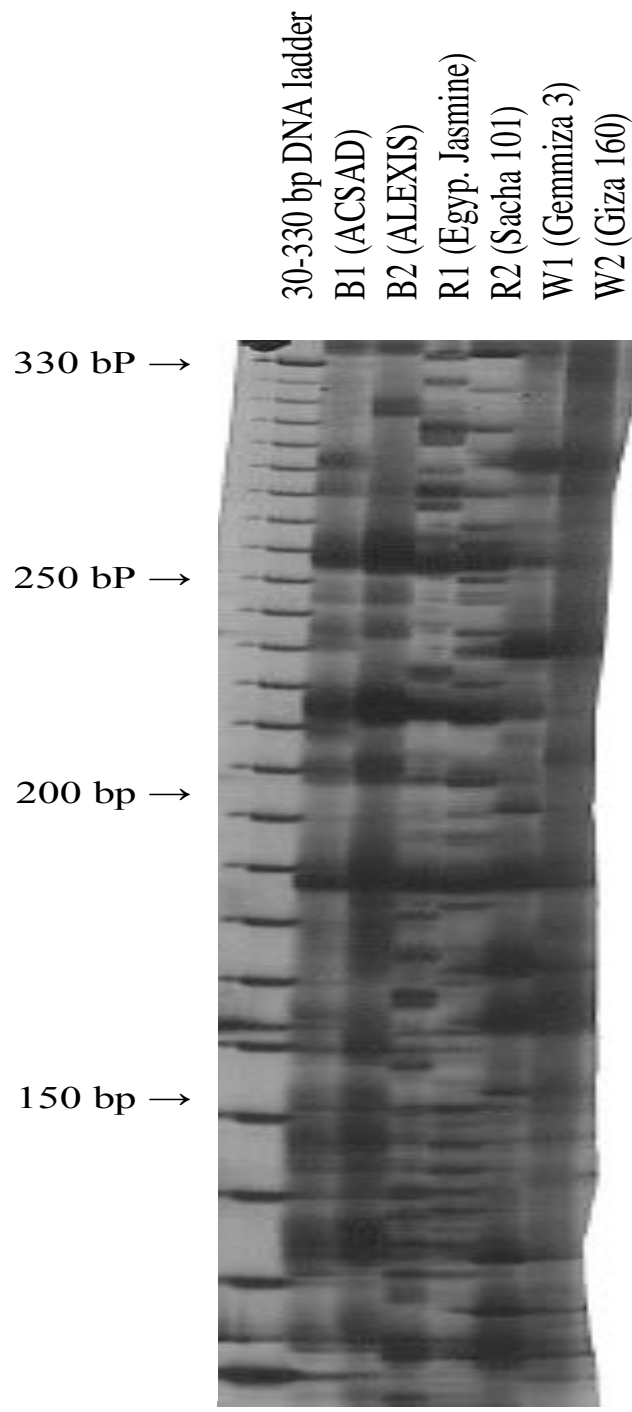

Figure 1. Examples of AFLP autoradiografic profiles of AFLP fragments of the six cereal cultivars using primer combination E36/M41. relationship between the three crops; barley, wheat and rice based on the AFLP data. Figure 2 shows the dendrogram representing the relationships between the three crops.

Barley and wheat cultivars are closely related to each other than to rice, which appeared little distant from both of them. At the same time, each two cultivars of the same crop were clustered together closer to each other than to those cultivars belonging to different species.

\section{Second experiment}

\section{Simple sequence repeats (SSR) analysis}

Thirty SSR markers with molecular weight ranges from 200 to $1300 \mathrm{bp}$ were produced as a result of amplification of the genomic DNA of the studied cereal genotypes using 11 SSR primers (Table 1). Figure 3 shows an example of amplified genomic DNA of the studied samples using primer MGB396. One SSR marker was resulted from each of the following primers: LEA (700 bp), MGB391 (200 bp), Bmag149 (850 bp), MGB356 (480 bp), Bmag210 (600 bp). Two markers were produced from MGB318 Primer (450, $580 \mathrm{bp})$, and three marker were produced from MGB396 primer $(200,260$, $300 \mathrm{bp}$ ) and four markers were produced using MGB402 primer (200, 280, 300, $320 \mathrm{bp}$ ) and MGB371 primer (200, $250,300,320 \mathrm{bp})$ and six markers were produced using primer MGB384 (250, 270, 420, 500, 720, $750 \mathrm{bp})$ and BMS02 primer (300, 320, 600, 1000, 1050, 1300 bp).

The relationship between the studied cereal cultivars based on simple sequence repeats (SSR) data analysis

The thirty SSR markers were analyzed using NTSYSPC2 program according to their appearance or absence 
Table 3. Frequency of AFLP markers in the studied cereal taxa of the first experiment.

\begin{tabular}{ccccccccccc}
\hline B1=H2 & R1+R2 & W1+W2 & $\begin{array}{c}\text { H1+H2+ } \\
\text { R1+R2 }\end{array}$ & $\begin{array}{c}\text { R1+R2+ } \\
\text { W1+W2 }\end{array}$ & $\begin{array}{c}\text { B1+B2+ } \\
\text { W1+W2 }\end{array}$ & $\begin{array}{c}\text { B1+or B2+ } \\
\text { R1+or R2 }\end{array}$ & $\begin{array}{c}\text { R1+or R2+ } \\
\text { W1+or W2 }\end{array}$ & $\begin{array}{c}\text { B1+or B2+ } \\
\text { W1+or W2 }\end{array}$ & $\begin{array}{c}\text { B1+or B2+W1+or } \\
\text { W2+ R1+or R2 }\end{array}$ & Total \\
\hline 12 & 50 & 28 & 20 & 20 & 35 & 21 & 29 & 21 & 64 & 300 \\
\hline
\end{tabular}

$\mathrm{B}=$ Barley, $\mathrm{R}=$ rice and $\mathrm{W}=$ wheat.

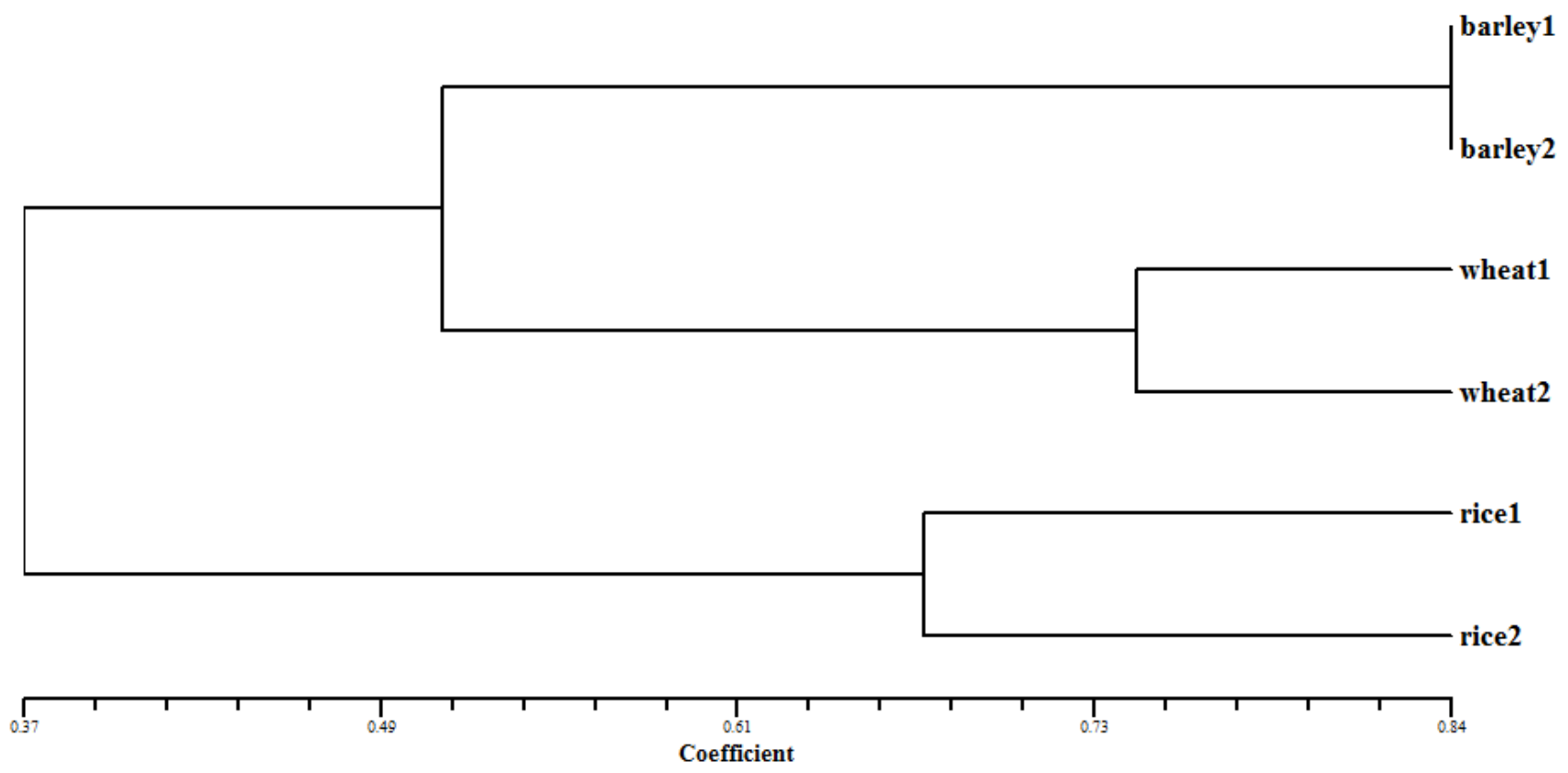

Figure 2. The relationships between barley, rice and wheat based on AFLP data and using NTSYS-pc.

to address the genetic relationship among the eight cereal cultivars as shown in Figure 4. The maize sample was clustered with the two sorghum samples in one group distant from the other taxa. The second group is divided into two sub groups the first one consists of four taxa containing all barley and wheat cultivars. The two wheat samples were grouped together and the other two cultivars of barley were grouped together. The other subgroup consists of rice which appeared more related to barley and wheat more than other cultivars.

\section{Inter simple sequence repeats (ISSR) analysis}

Ninety one ISSR markers ranged from 200 to $1500 \mathrm{bp}$ were obtained as a result of fingerprinting the eight cereal samples under study using the 10 ISSR primers indicated in Table 2 as follows: eight markers ranging from 380 to $680 \mathrm{bp}$ were obtained using primer 814, nine ISSR markers ranging from 400 to $1100 \mathrm{bp}$ were obtained using primer $844 \mathrm{~A}$, seven markers ranging from 380 to $1100 \mathrm{bp}$ were obtained using primer $844 \mathrm{~B}$, six markers ranging from 650 to $1200 \mathrm{bp}$ were obtained using primer $\mathrm{HB}$ 8, ten markers ranging from 420 to $1500 \mathrm{bp}$ were obtained using primer HB 9, eleven markers ranging from 300 to 900 bp were obtained using primer HB 10, seven marker ranging from 240 to $700 \mathrm{bp}$ were obtained using primer HB 11, nine markers ranging from 300 to $750 \mathrm{bp}$ were obtained using primer $\mathrm{HB} 13,17$ markers ranging from 200 to $1200 \mathrm{bp}$ were obtained using primer HB 14 and seven markers ranging from 250 to $1400 \mathrm{bp}$ were obtained using primer HB 15. Figure 5 shows an example of ISSR-PCR using HB14 ISSR primer.

\section{The relationship between the studied cereal cultivars based on ISSR data analysis}

The resulted 90 ISSR data were analyzed using NTSYSPC2 program to address the genetic relationship among the eight cereal cultivars as shown in Figure 6 . The result of the ISSR data analysis is nearly similar to that produced from SSR data analysis. The two wheat genotypes were grouped together and appeared close relatedness to the the two barley cultivars of barley that were grouped also together. The rice sample revealed high relatedness to both barley and wheat genotypes followed by sorghum and maize that appeared distant from all genotypes. 


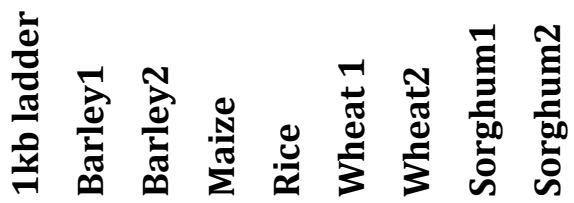

$10000 \mathrm{bp} \rightarrow$

$6000 \mathrm{bp}-$

$5000 \mathrm{bp} \rightarrow$

$4000 \mathrm{bp} \rightarrow$

$3000 \mathrm{bp} \rightarrow$

$2000 \mathrm{bp}-$

$1500 \mathrm{bp} \rightarrow$

$1000 \mathrm{bp} \rightarrow$

$700 \mathrm{bp} \rightarrow$

$500 \mathrm{bp} \rightarrow$

$300 \mathrm{bp} \rightarrow$

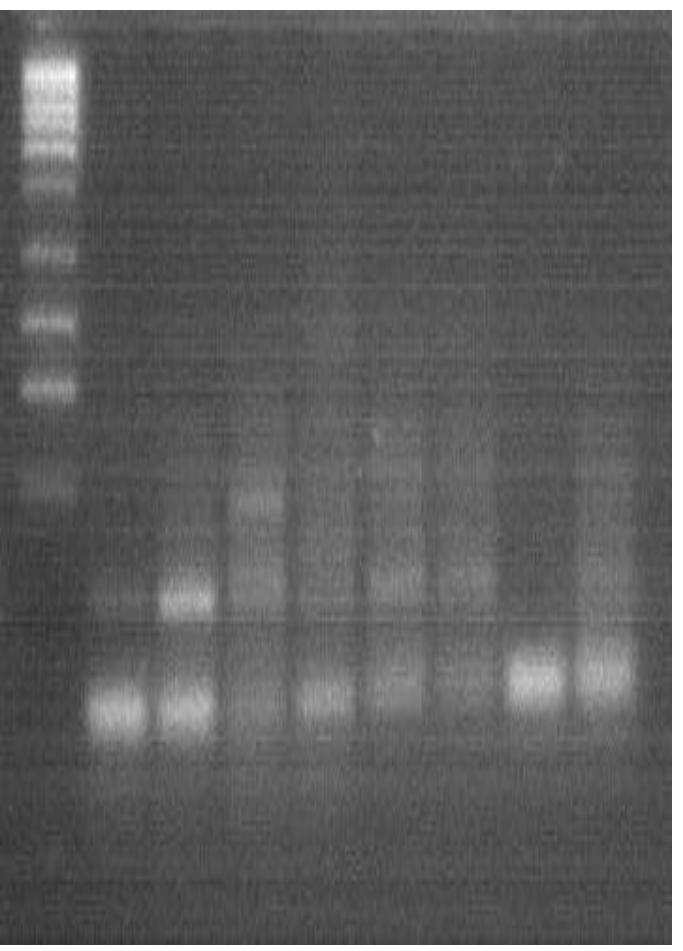

Figure 3. Examples of amplified genomic DNA of the studied cereal samples using primer for MGB396 SSR marker.

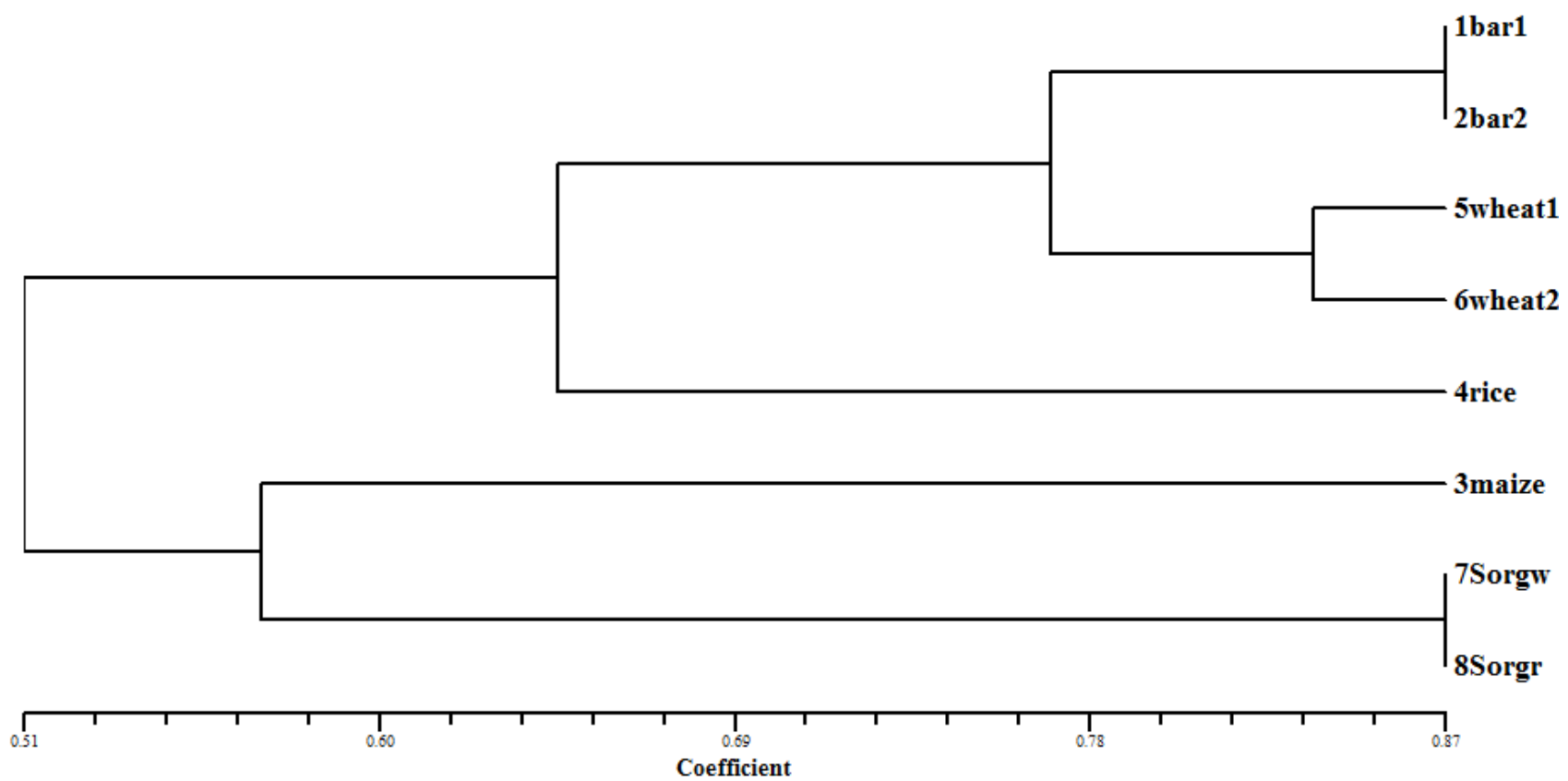

Figure 4. The relationship of the studied cultivars based on SSR data analysis using NTSYS-pc program. 


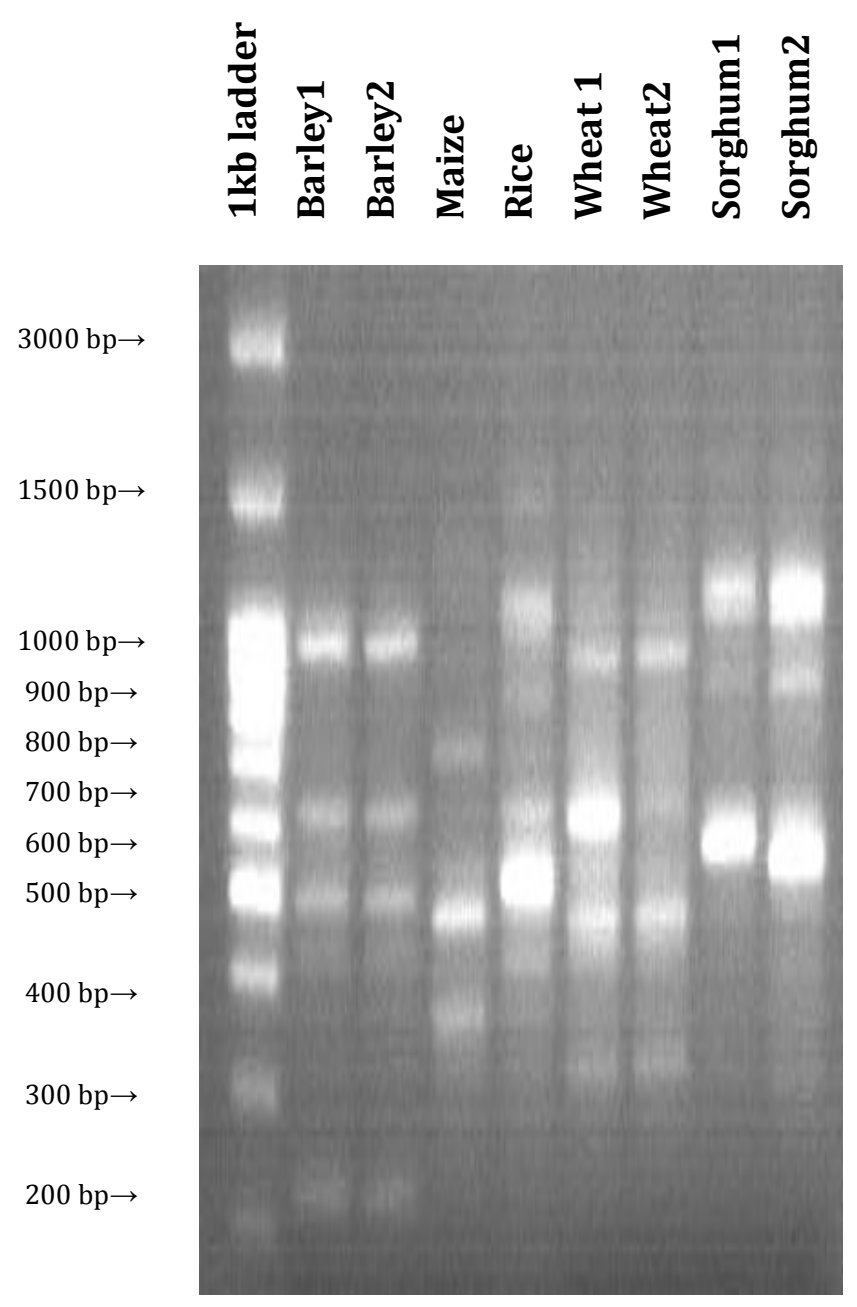

Figure 5. Amplified ISSR markers of the studied cereal genomic DNA using HB14 ISSR primer.

\section{DISCUSSION}

The phylogenetic studies based on AFLP, SSR and ISSR are considered based on DNA sequence homology of the studied genotypes, because the common bands are considered similar in DNA sequence data. All the resulted dendrograms based on AFLP, SSR and ISSR using NTSYS-pc program revealed that barley and wheat are more related to each other than to rice, followed by sorghum and maize. This result is consistent with the phylogenetic studies and taxonomy of Poaceae (Mathews et al., 2000; Bolot et al., 2009) because wheat and barley belong to Triticeae, rice belongs to Oryzeae, whereas maize and sorghum belong to Andropogoneae. The presence of homologous DNA sequences consensus within cereal genomes is also consistent with many studies and emphasized that all cereal crops are closely related to each other and the whole group of Triticeae can be considered as a single gene pool because of the similarity of genetic contents and the co-linearity of gene loci of the chromosomes of barley and other members of Triticeae particularly wheat and to a limited and partially useful synteny between wheat and rice chromosomes (Islam, 1983; Islam and Shepherd, 1992; Mohler and Jahoor, 1996; Gallego et al., 1998; Bolot et al., 2009; Kumar et al., 2010).

This ultimate relationship has also been emphasized by the relatively high number of protein and AFLP markers common to wheat and barley compared to those common to rice. Meanwhile, Hartl and Jones (2001) stated that each chromosome in wheat contains approximately 25 times as much DNA as each chromosome in rice. The relatively high number of markers common to all the three taxa but polymorphic in one or more samples emphasize the fact of colinearity or synteny present within the three taxa (SanMiguel et al., 1996; Mohler and Jahoor, 1996; Chen et al., 1997; Gale and Devos, 1998; Dennis, 2001). Mahalakshmi (2001) used the public databases of model 


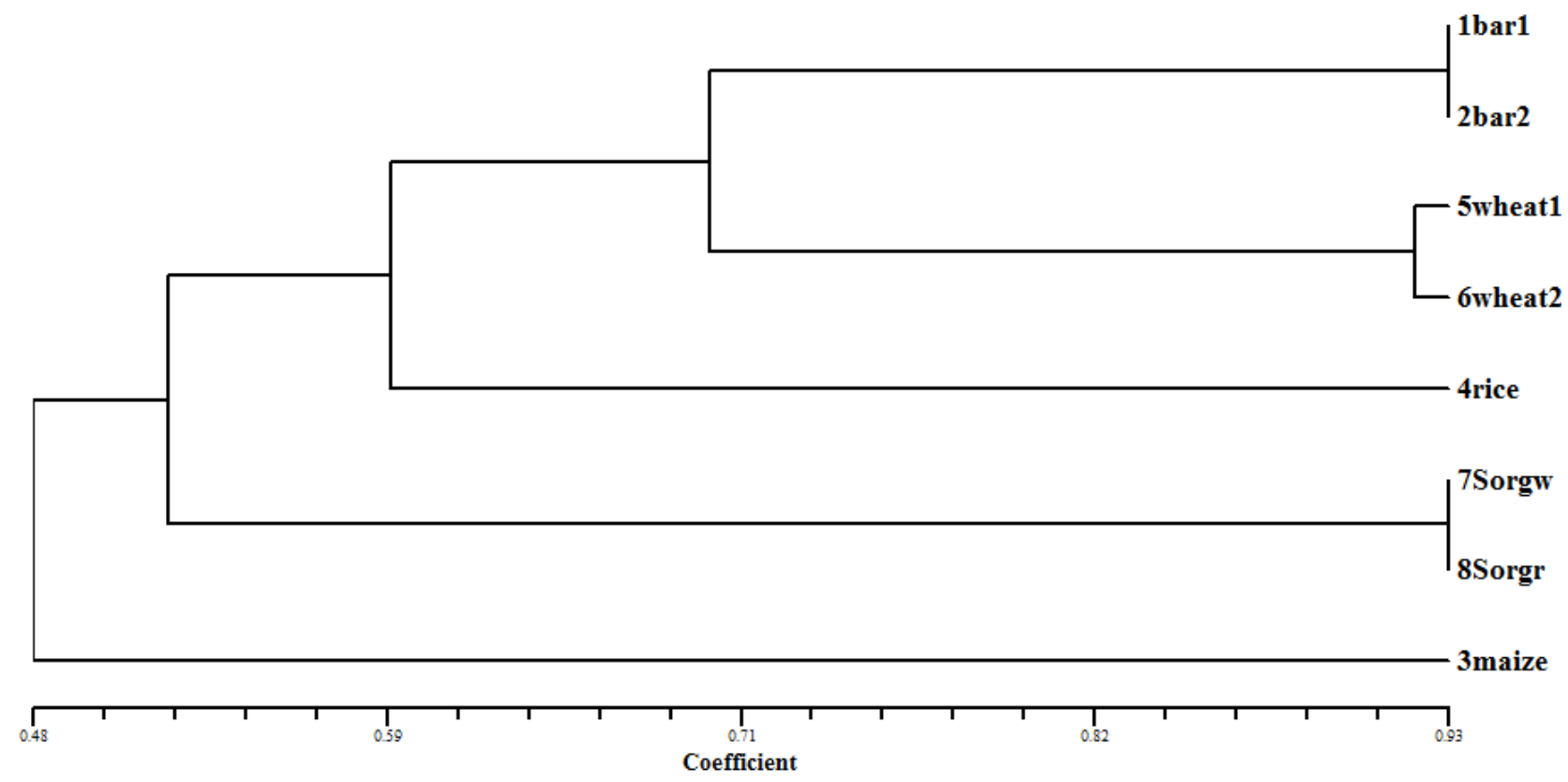

Figure 6. The relationship of the studied cultivars based on ISSR data analysis using NTSYS-pc program.

organisms and bio-informatics in data mining and the more focused molecular tools for gene discovery and deployment in describing an approach to benefit sorghum [Sorghum bicolor (L.) Moench] grown in a rain fed semiarid tropical areas by studying synteny between rice and sorghum comparison of the consensus map of them. The relative co-linearity or synteny within cereal crops was evident by previous studies (Dennis, 2001; Ramakrishna et al., 2002; Liu et al., 2006; Messing, 2009). Kumar et al. (2010) surveyed the role of allele mining in cereal and other crops phylogeny. They clarified the role of rubi3 (polyubiquitin gene) (Samadder et al., 2008) in rice, VRN1 (which affect vernalization response) in barley and wheat (Fu et al., 2005). Moore (1992) reported that, although wheat has one of the largest genomes $(1.7 \times$ $\left.10^{10} \mathrm{bp}\right)$ and rice has one of the smallest plant genomes $\left(4 \times 10^{8} \mathrm{bp}\right)$. It has been observed that a significant microsynteny is present between the two genomes. Meanwhile, Gallego et al. (1998) reported that comparative genetic mapping among cereal genomes has demonstrated that homologous single-copy sequences or genes are collinear on the RFLP maps of wheat, barley, rye, oat, maize and rice. This has allowed the maps of several members of the Gramineae family to be compared and the synteny of these genomes to be defined. The Lr10 leaf rust resistance gene on wheat chromosome 1 AS cosegregates with the Lrk10 receptor-like kinase gene. The rice gene corresponding to Lrk10 is mapped on rice chromosome 1. This region corresponds to the distal part of barley chromosome $3 \mathrm{H}$ and wheat chromosomes $3 \mathrm{~A}$ and $3 \mathrm{~B}$, suggesting that the synteny is conserved between rice chromosome 1 and the Triticeae group $3 S$ chromosomes up to the telomere of the chromosomes.

Several researchers are interested in studying synteny between barley and rice genomes. Korzun, and Kunzel (1996) using polymerase chain reaction (PCR)-mediated approach for physical mapping of single-copy DNA sequences on microisolated chromosomes of barley, sequence-tagged sites of DNA probes that reveal RFLP localized on the linkage maps of rice chromosomes 5 and 10 were allocated to cytologically defined regions of barley chromosome $5(1 \mathrm{H})$. Leister et al. (1999) found homology of resistance genes present in both barley and rice. At the same time, Druka et al. (2000) found that a synteny at high resolution levels has been established between the region of barley chromosome $7(5 \mathrm{H})$ containing the rpg4 locus and the subtelomeric region of rice chromosome 3 between markers S16474 and E10757. Smilde et al. (2001) scored a synteny between rice chromosome 1 and barley chromosome $3 \mathrm{H}$ using rice expressed sequence tags. The current result is greatly consistent with the phylogeny tree of Bolot et al. (2009).

El Rabey et al. (2002) compared common bands isolated from different Hordeum species, $80.05 \%$ of these bands were found homologous in DNA sequence. Therefore, the intercultivars relationships based on AFLP data are considered a relationship based on sequence data. This research will also highlights the benefits for sharing information in the public domain and the role of bioinformatics in enhancing crops productivity and resistance to diseases and severe conditions. Furthermore, it will help in understanding that the structure and function of one gene within these crops will help develop new measures against disease control in the other crops. 
This will open the door for studying the quantitative trait loci (QTLs) correlated to specific economic traits of the cultivated crop plants. Eventually, synteny, or preservation of the order of genes on a chromosome of one of these crops, can be a marker for evolutionary history, or a key to functional relationships between genes from the other crops under study or other related organisms as well as increasing their productivity and disease control.

\section{ACKNOWLEDGMENT}

The project was funded by the Deanship of Scientific Research (DSR), King Abdulaziz University, Jeddah, under grant no. 20 to 130 to 1431. The authors, therefore, acknowledge with thanks DSR technical and financial support.

\section{REFERENCES}

Akagi H, Yokozeki Y, Inagaki A, Fujimura T (1996). Microsatellite DNA markers for the rice chromosomes. Theor. Appl. Genet. 93:10711077.

Bachmann K (1998). Species as units of diversity: and outdated concept. Theor. Biosci. 117: 213-230.

Badr A, Mueller K, Schaefer-Pregl R, El Rabey H, Effgen S, Ibrahim H, Pozzi C, Rohde W, Salamini F (2000). On the origin and domestication history of barley ( $H$. vulgare). Mol. Biol. Evol. 17(4):499-510.

Becker J, Vos P, Kuiper M, Salamini F, Heun M (1995). Combined mapping of AFLP and RFLP markers in barley. Mol. Gen. Genet. 249: 65-73.

Bennetzen JL, May J (2003). The genetic colinearity of rice and other cereals on the basis of genomic sequence analysis. Curr. Opin. Plant Biol. 6:128-133.

Bolot S, Abrouk M, Masood-Quraishi U, Stein N, Messing J, Feuillet C, Salse J (2009). The 'inner circle' of the cereal genomes. Curr. Opin. Plant Biol., 12: 119-125.

Buell R, Yuan Q, Ouyang S, Liu J, Zhu W, Wang A, Maiti R, Haas B (2005). Sequence, annotation, and analysis of synteny between rice chromosome 3 and diverged grass species; The Rice Chromosome 3 Sequencing Consortium. Genome Res. 15:1284-1291.

Burkhamer RL, Lanning SP, Martens RJ, Martin JM, Talbert LE (1998). Predicting progeny variance from parental divergence in hard red spring wheat. Crop Sci. 38(1):243-248.

Chen M, SanMiguel P, Oliviera AC, Woo S-S, Zhang H, Wing RA, Bennetzen JL (1997). Microcolinearity in the sh2-homologous regions of the maize, rice and Sorghum genomes. Proc. Natl. Acad. Sci. USA, 94:3431-3435.

Dennis ES (2001). Genomics and its relevance to barley. Proceedings of the 10th Australian Barley Technical Symposium.

Druka A, Kudrna D, Han F, Kilian A, Steffenson B, Frisch D, Tomkins J, Wing R, Kleinhofs A (2000). Physical mapping of the barley stem rust resistance gene rpg4. Mol. Gen. Genet. 264(3):283-289.

El Rabey H, Badr A, Schaefer-Pregl R, Martin W, Salamini F (2002). Speciation and Species Separation in Hordeum L. (Poaceae) Resolved by Discontinuous Molecular Markers. Plant Biol. 4:1-9.

El Rabey H, Abbas N, Osman M (2006). DNA and seed proteins fingerprinting of Egyptian crop plants. VI. The genetic characterization of seven maize hybrids (Zea mays L.). Proceeding of the second international conference on genetic engineering and its applications, 11-15 November, Sharm El Sheikh, Egypt. pp. 145-156.

FAO (1985). FAO Production Year Book. 37:107-122.

Fu D, Szucs P, Yan L, Helguera M, Skinner JS, von Zitzewitz J (2005). Large deletions within the first intron in VRN-1are associated with spring growth habit in barley and wheat. Mol. Gen. Genomics, 273: 54-65.
Gale MD, Devos KM (1998). Plant comparative genetics after 10 years. Science 282: 656-659.

Gallego F, Feuillet C, Messmer M, Penger A, Graner A, Yano M, Sasaki $\mathrm{T}$, Keller B (1998). Comparative mapping of the two wheat leaf rust resistance loci $L r 1$ and $L r 10$ in rice and barley. Genome 41:328-336.

Gustafson JP, Yano M (2000). Genetic mapping of hypervariable minisatellite sequences in rice (Oryza sativa). The Appl. Gen. Abst. 100:447-453.

Hartl DL, Jones EW (2001). Genome evolution in the grass family. In, Genetics and analysis of genes and genomes. Fifth edition, Jones and Bartlett publishers/Sudbury, Massachusetts, USA.

Heun M, Schaefer-Pregl R, Klawan D, Castagna R, Accerbi M, Borghi B, Salamini F (1997). Site of Einkorn wheat domestication identified by DNA fingerprinting. Science 278:1312-1314.

Huang X, Zeller F, Hsam S, Wenzel G, Mohler V (2000). Chromosomal location of AFLP markers in common wheat utilizing nulli-tetrasomic stocks. Genome 43:298-305.

Islam A (1983). Ditelosomic additions of barley chromosomes to wheat. In proc. $6^{\text {th }}$ Int. Wheat genet. Symp., Koyoto (ed. S Sakamoto), Maruzen, Koyoto. 233-238.

Islam A, Shepherd K (1992). Substituting ability of individual barley chromosomes for wheat chromosomes. 1. Substitution involving barley chromosomes 1, 3 and 6. Plant breed 109:141-150.

Korzun L, Kunzel G (1996). The physical relationship of barley chromosome $(1 \mathrm{H})$ to the linkage group of rice chromosomes 5 and 10. Mol. Gen. Genet. 253 (1-2):225-231.

Kumar GR, Sakthivel K, Sundaram RM, Neeraja CN, Balachandran SM, Rani NS, Viraktamath BC, Madhav MS (2010). Allele mining in crops: Prospects and potentials. Biotechnol. Adv. 28:451-461.

Leister D, Kurth J, Laurie D, Jano M, Sasaki T, Graner A and SculzeLefert P (1999): RFLP and physical mapping of resistance gene homologues in rice (O. sativa) and Barley ( $H$. vulgare). Theor. Appl. Genet. 98(34):509-520.

Liu S, Zhang X, Pumphrey MO, Stack RW, Gill BS, Anderson JA (2006). Complex microcolinearity among wheat, rice, and barley revealed by fine mapping of the genomic region harboring a major QTL for resistance to Fusarium head blight in wheat. Funct. Integr. Genomics 6(2):83-89.

Mackill D, Zhang Z, Redona E, Colowit P (1995). AFLP markers for rice genetic study. Plant Genome IV Conference, San Diego, California, USA, p. 71.

Mahalakshmi V (2001). Plant genomics and agriculture: From model organisms to crops, the role of data mining for gene discovery. Electron. J. Biotechnol. 4(3):9-10. ISSN. 0717-3458.

Mathews SM, Tsai RC and Kellogg EA (2000). Phylogenetic structure in the grass family (Poaceae): evidence from the nuclear gene phytochrome B. Am. J. Bot. 87(1):96-107.

Messing J (2009). Update on Genomes of the Grass Family, Synergy of Two Reference Genomes for the Grass Family1. Plant Physiol. 149: 117-124.

Mohler V, Jahoor A (1996). Allele specific amplification of polymorphic sites for the detection of powdery mildew resistance loci in cereals. Theor. Appl. Genet. 93(7):1078-1082.

Moore G (1992). Beyond the map: Genome analysis of small grain cereals. Plant Genome I Conference, Town and Country Conference Center, San Diego, California, USA.

Moore G, Devos KM Wang Z, Gale MD (1995): Cereal genome evolution. Curr. Biol. 5:737-739.

Powell W, Morgante M, Andre C, Hanafey M, Vogel MJ, Tingey SV. Rafalski A (1996). The comparison of RFLP, RAPD, AFLP and SSR (microsatellites) markers for germplasm analysis. Mol. Breed. 2:225235.

Ramakrishna W, Dubcovsky J, Park Y, Busso C, Emberton, J, SanMiguel P, Bennetzen JL (2002). Different Types and Rates of Genome Evolution Detected by Comparative Sequence Analysis of Orthologous Segments From Four Cereal Genomes. Genetics 162: 1389-1400.

Rohlf FJ (1993). NTSYS-pc. Numerical Taxonomy and Multivariate Analysis System. Applied Biostatistics Inc, New York. p. 91

Saghai-Maroof MA, Soliman KM, Jorgensen RA, Allard RW (1984). Ribosomal DNA spacer-length polymorphism in barley. Mendelian inheritance, chromosomal location, and population dynamics. Proc. 
Natl. Acad. Sci. USA., 81:8014-8018.

Samadder P, Sivamani E, Lu J, Li X, Qu R (2008). Transcriptional and post-transcriptional enhancement of gene expression by the $5^{\prime}$ UTR intron of rice rubi3 gene in transgenic rice cells. Mol. Genet.

Genomics 279:429-39.

SanMiguel P, Tikhonov A, Jin Y-K, Motchoulskaia N, Zakharov D, Melake-Berhan A, Springer PS, Edwards KJ, Lee M, Avramova Z, Bennetzen JL (1996). Nested retrotransposons in the intergenic regions of the maize genome. Science 274:765-768.

Smilde W, Haluskova J, Sasaki T, Graner A (2001). New evidence for the synteny of rice chromosome 1 and barley chromosome $3 \mathrm{H}$ from rice expressed sequence tags. Genome 44:361-367.

Sneath PHA, Sokal RR (1973): Numerical taxonomy. Freeman, San Francisco, California.

Sokal RR, Michener CD (1958). A statistical method for evaluating systematic relationships. University of Kansas Sci. Bull. 28:14091438.

Temnykh S, DeClerck G, Lukashuva A, Lipovich L, Cartinhour S, Susan McCouch (2000). Mapping and genome organization of microsatellite sequences in rice (Oryza sativa L.). Theor. Appl. Genet. 100697.

Vos P, Hogers R, Bleeker M, Reijans M, Lee T van de, Hornes M,

Frijters A, Pot J, Peleman J, Kuiper M, Zabeau M (1995). AFLP: a new technique for DNA fingerprinting. Nucleic Acids Res. 23(21):44074414.
Wicker T, Krattinger SG, Lagudah ES, Komatsuda T, Pourkheirandish M, Matsumoto T, Cloutier S, Reiser L, Kanamori H, Sato K, Perovic D, Stein N and Keller B (2009). Analysis of intraspecies diversity in wheat and barley genomes identifies breakpoints of ancient haplotypes and provides insight into the structure of diploid and hexaploid Triticeae gene pools. Plant Physiol. (149):258-270.

Winfield MO, Arnold GM, Cooper F, Le Ray M, White J, Karp A, Edwards KJ (1998). A study of genetic diversity in Populus nigra subsp. Betulifolia in the upper Severn area of the UK using AFLP markers. Mol. Ecol. 7:3-10.

Yang L, Bennetzen JL (2009). Distribution, diversity, evolution, and survival of Helitrons in the maize genome. Proc. Natl. Acad. Sci. U S A 106(47):19747-19748.

Yu J, Hu S, Wang J, Wong GK (2002). A draft sequence of the rice genome (Oryza sativa L. ssp. indica). Science 5:296(5565):79-92. 